\title{
Chronic administration of caderofloxacin, a new fluoroquinolone, increases hepatic CYP2E1 expression and activity in rats
}

\author{
Li LIU ${ }^{1}$, Ming-xing MIAO², Ze-yu ZHONG ${ }^{1}$, Ping XU ${ }^{1}$, Yang $\mathrm{CHEN}^{1}$, Xiao-dong LIU ${ }^{1, *}$
}

\begin{abstract}
${ }^{1}$ Center of Drug Metabolism and Pharmacokinetics, College of Pharmacy, China Pharmaceutical University, Nanjing 210009, China; ${ }^{2}$ Experimental and Teaching Center of Medical Basis for Pharmacy, College of Pharmacy, China Pharmaceutical University, Nanjing 210009, China
\end{abstract}

\begin{abstract}
Aim: Caderofloxacin is a new fluoroquinolone that is under phase III clinical trials in China. Here we examined the effects of caderofloxacin on rat hepatic cytochrome P450 (CYP450) isoforms as well as the potential of caderofloxacin interacting with co-administered drugs.

Methods: Male rats were treated with caderofloxacin $(9 \mathrm{mg} / \mathrm{kg}$, ig) once or twice daily for 14 consecutive days. The effects of caderofloxacin on CYP3A, 2D6, 2C19, 1A2, 2E1 and 2C9 were evaluated using a "cocktail" of 6 probes (midazolam, dextromethorphan, omeprazole, theophylline, chlorzoxazone and diclofenac) injected on d 0 (prior to caderofloxacin exposure) and d 15 (after caderofloxacin exposure). Hepatic microsomes from the caderofloxacin-treated rats were used to assess CYP2E1 activity and chlorzoxazone metabolism. The expression of CYP2E1 mRNA and protein in hepatic microsomes was analyzed with RT-PCR and Western blotting, respectively.

Results: Fourteen-day administration of caderofloxacin significantly increased the activity of hepatic CYP2E1, leading to enhanced metabolism of chlorzoxazone. In vitro microsomal study confirmed that CYP2E1 was a major metabolic enzyme involved in chlorzoxazone metabolism, and the 14-d administration of caderofloxacin significantly increased the activity of CYP2E1 in hepatic microsomes, resulting in increased formation of 6-hydroxychlorzoxazone. Furthermore, the 14-d administration of caderofloxacin significantly increased the expression of CYP2E1 mRNA and protein in liver microsomes, which was consistent with the pharmacokinetic results.

Conclusion: Fourteen-day administration of caderofloxacin can induce the expression and activity of hepatic CYP2E1 in rats. When caderofloxacin is administered, a potential drug-drug interaction mediated by CYP2E1 induction should be considered.
\end{abstract}

Keywords: caderofloxacin; cocktail approach; chlorzoxazone; CYP2E1; pharmacokinetics; drug-drug interaction

Acta Pharmacologica Sinica (2016) 37: 561-570; doi: 10.1038/aps.2015.160; published online 1 Feb 2016

\section{Introduction}

Caderofloxacin lactate, (1-cyclopropyl-6-fluoro-8-difluoromethoxy-1,4-dihydro-7-[(3S)-methyl-1-piperazinyl]-4-oxo3-quinolinecarboxylic acid lactate), which is derivatized from ciprofloxacin, is a newly developed active quinolone carboxylic acid. Initial susceptibility studies have documented that caderofloxacin is effective against aerobic/anaerobic Grampositive and Gram-negative bacteria and exhibits antibacterial activity that is markedly superior to ciprofloxacin against $S$ aureus and $P$ aeruginosa $a^{[1-3]}$. Pharmacokinetic studies com-

\footnotetext{
* To whom correspondence should be addressed.

E-mail xdliu@cpu.edu.cn

Received 2015-07-09 Accepted 2015-10-22
}

pleted in our laboratory showed that caderofloxacin is well absorbed and has a high oral bioavailability, a good tissue distribution, and favorable elimination half-life properties. Currently, it is in Phase III clinical trials in China. Therefore, its influence on CYP450 is very important for its further study and clinical use.

The CYP enzyme family consists of multiple isoforms with different substrate specificities and catalyzes the biotransformation of a vast number of drugs ${ }^{[4]}$. The CYPs are further divided into several subfamilies based on their amino acid sequence similarities. Six of the CYPs, CYP1A2, CYP3A, CYP2C9, CYP2C19, CYP2D6, and CYP2E1, play a major role in drug metabolism ${ }^{[5]}$. Their probes have been widely used to evaluate the activities of the individual CYPs in the field of 
drug metabolism ${ }^{[6]}$. The cocktail approach involves the administration of multiple probes simultaneously and the measurement of the plasma kinetics of probes ${ }^{[7,8]}$, which is more convenient and saves costs and time compared with single-probe substrate studies ${ }^{[9-12]}$. In this study, a "cocktail" approach with the probes theophylline (CYP1A2), midazolam (CYP3A), chlorzoxazone (CYP2E1), dextromethorphan (CYP2D6), omeprazole (CYP2C19) and diclofenac (CYP2C9) ${ }^{[13,14]}$ were used to investigate whether caderofloxacin affects the activity of its corresponding CYPs in rats.

\section{Materials and methods} Chemicals and reagents

Caderofloxacin was obtained from the Harbin Pharmaceutical Group Co, Ltd (Harbin, China). Theophylline, midazolam, chlorzoxazone, dextromethorphan, omeprazole, diclofenac, diazepam (Internal Standard 1, IS1), and chlorpropamide (Internal Standard 2, IS2) were purchased from the National Institute for the Control of Pharmaceutical and Biological Products (Beijing, China). Glucose-6-phosphate, glucose6-phosphate dehydrogenase, $\beta$-nicotinamide adenine dinucleotide phosphate (NADP) and 6-hydroxychlorzoxazone were purchased from Sigma-Aldrich (St Louis, MO, USA). Methanol and acetonitrile were of chromatographically pure grade and purchased from Merck (Merck Company, Germany). All other chemicals and solvents used were of analytical grade or chemical grade.

\section{Animals}

Male Sprague-Dawley rats weighing 180-220 g were obtained from Sino-British Sipper \& BK Lab Animal, Ltd (Shanghai, China). The rats were maintained at ambient temperature $\left(23 \pm 1^{\circ} \mathrm{C}\right)$ and relative humidity $(50 \% \pm 10 \%)$ with a $12 \mathrm{~h}$ light/ darkness cycle and were allowed free access to water and food. Animal experiments were carried out according to the Institutional Guidelines for the Care and the Use of Laboratory Animals and were approved by the Animal Ethics Committee of China Pharmaceutical University.

An assessment of the effects of caderofloxacin on the activities of cytochrome $\mathrm{P} 450$ isozymes in rats using a cocktail approach

Protocol 1: Twelve rats were randomly divided into two groups. Midazolam $(2 \mathrm{mg} / \mathrm{kg})$, dextromethorphan $(5 \mathrm{mg} / \mathrm{kg})$ and omeprazole $(2 \mathrm{mg} / \mathrm{kg})$ were intravenously administered to one group, while theophylline $(1 \mathrm{mg} / \mathrm{kg})$, chlorzoxazone $(1 \mathrm{mg} / \mathrm{kg})$ and diclofenac $(0.5 \mathrm{mg} / \mathrm{kg})$ were administered to the other. Blood samples (with a volume of approximately 0.2 $\mathrm{mL}$ ) were collected under light ether anesthesia via the postorbital venous plexus veins in heparinized tubes at 2, 5, 15, $30,60,90,120,180,240,360$, and 480 min after midazolam, dextromethorphan and omeprazole administration and at 5 , $15,30,60,90,120,180,240,360,480$, and $720 \mathrm{~min}$ for theophylline, chlorzoxazone and diclofenac administration. After 3 or 4 samplings, the equivalent amount of normal saline was administered to the rats via the tail vein to compensate for the blood loss. The samples were centrifuged, and the plasma was separated and frozen at $-20^{\circ} \mathrm{C}$. After $7 \mathrm{~d}$ of washing out, the same procedures and dosages were completed again $15 \mathrm{~min}$ following the oral administration of caderofloxacin $(9 \mathrm{mg} / \mathrm{kg})$.

Protocol 2: On the $1^{\text {st }} \mathrm{d}$, the procedures and dosages were used as those described in Protocol 1. Six probes were given, and the plasma samples were obtained and stored. On the $2^{\text {nd }} \mathrm{d}$, all animals were given $9 \mathrm{mg} / \mathrm{kg}$ of caderofloxacin through an intragastrical administration twice daily for 14 $\mathrm{d}$. On the $15^{\text {th }} \mathrm{d}$, the same procedures and dosages were performed again.

The effects of the chronic administration of caderofloxacin on the pharmacokinetics of chlorzoxazone in rats

Twelve rats were divided into 2 groups. Group 1 served as the age-matched control and only received vehicle. Group 2 was orally administered $9 \mathrm{mg} / \mathrm{kg}$ of caderofloxacin twice daily for $14 \mathrm{~d}$. On the 15th $\mathrm{d}$, all rats were fasted for $12 \mathrm{~h}$ and intravenously administered $1 \mathrm{mg} / \mathrm{kg}$ of chlorzoxazone via the tail vein. Blood samples $(0.25 \mathrm{~mL})$ were collected under light ether anesthesia via the oculi chorioideae vein at 5, 10, 20, $30,45,60,90,120,180$ and 240 min after the dose was administered. After centrifugation at $3000 \times \mathrm{g}$ for $10 \mathrm{~min}$, plasma samples were obtained and stored at $-20^{\circ} \mathrm{C}$ until analysis. On d 16, animals from each group were sacrificed under light ether anesthesia, and their livers were quickly harvested for the preparation of hepatic microsomes, QT-PCR and Western blot analysis.

The preparation of hepatic microsomes and the metabolism of chlorzoxazone in hepatic microsomes

Hepatic microsomes were prepared fresh from the agematched control and caderofloxacin treated rats mentioned above, according to methods described previously ${ }^{[15]}$. The rats were sacrificed under light ether anesthesia, and their livers were quickly harvested. The microsomal pellets were resuspended in $0.1 \mathrm{~mol} / \mathrm{L}$ phosphate-buffered saline $(\mathrm{pH} 7.4)$ containing $30 \%$ glycerol and were stored at $-80{ }^{\circ} \mathrm{C}$. The protein concentrations were measured by using the method described by Bradford, with bovine serum albumin as the standard.

Chlorzoxazone is mainly metabolized into 6-hydroxychlorzoxazone via CYP2E1-mediated 6-hydroxylation, and the formation of 6-hydroxychlorzoxazone is used as a marker for assessing CYP2E1 activity. Preliminary experiments showed that the formation of 6-hydroxychlorzoxazone was linear for incubation times up to $20 \mathrm{~min}$ in $0.2 \mathrm{mg} / \mathrm{mL}$ of rat hepatic microsomes. Briefly, hepatic microsomes $(0.5 \mathrm{mg} / \mathrm{mL})$ were incubated for $20 \mathrm{~min}$ at $37^{\circ} \mathrm{C}$ with chlorzoxazone (5-1000 $\mu \mathrm{mol} / \mathrm{L})$ and an NADPH generating system $(0.5 \mathrm{mmol} / \mathrm{L}$ NADP, $10 \mathrm{mmol} / \mathrm{L}$ glucose-6-phosphate, $1 \mathrm{U} / \mathrm{mL}$ glucose6-phosphate dehydrogenase, and $5 \mathrm{mmol} / \mathrm{L} \mathrm{MgCl}_{2}$ ) in a final volume of $200 \mu \mathrm{L}$. The reaction was terminated with the addition of $20 \mu \mathrm{L}$ of $1 \mathrm{~mol} / \mathrm{L} \mathrm{HCl}$. All incubations were performed in triplicate. The formation of 6-hydroxychlorzoxazone from chlorzoxazone was used to measure the kinetic parameters of the reaction. 
The effects of diethyldithiocarbamate on chlorzoxazone metabolism in caderofloxacin-treated hepatic microsomes

To determine the inhibitory effect of CYP2E1 on chlorzoxazone metabolism, diethyldithiocarbamate (DDC), a CYP2E1 inhibitor, was used. DDC is considered to be a selective inhibitor of CYP2E1 and was used to evaluate the role of CYP2E1 in chlorzoxazone metabolism in rats. DDC (12.5 or $25 \mu \mathrm{mol} / \mathrm{L})$ was added to an incubation mixture $(200 \mu \mathrm{L})$ containing 0.5 $\mathrm{mg} / \mathrm{mL}$ rat hepatic microsomes and $100 \mu \mathrm{mol} / \mathrm{L}$ of chlorzoxazone, and the process was performed according to the method described above. After $20 \mathrm{~min}$ of incubation, the reaction was terminated with the addition of $20 \mu \mathrm{L}$ of $1 \mathrm{~mol} / \mathrm{L} \mathrm{HCl}$. The amount of 6-hydroxychlorzoxazone formed in the reaction mixture was determined.

\section{The measurement of CYP2E1 mRNA expression}

Quantitative real-time reverse transcription polymerase chain reaction (QT-PCR) was used to measure the levels of CYP2E1 mRNA in the liver ${ }^{[16]}$. The total RNA was extracted from the frozen livers using the TRIzol reagent (Invitrogen Co, Carlsbad, CA, USA) according to the manufacturer's instructions. The quality and purity of the RNA were assessed by UV spectrophotometry at $260 \mathrm{~nm}$ and $280 \mathrm{~nm}$. QT-PCR was performed using a cDNA input converted from $2 \mu \mathrm{g}$ of total RNA. The primer sequences were as follows: forward 5'-GAACTGAGACCACCAGCACAA-3' and reverse 5'-GATCTCATGCACCACAGCATC-3' for the CYP2E1 gene and forward 5'-CAGGTCATCACTATCGGCAAT-3' and reverse 5'-TGGCATAGAGGTCTTTACGGA-3' for the $\beta$-actin gene. After denaturing at $95^{\circ} \mathrm{C}$ for $2 \mathrm{~min}$, the amplification was obtained using 40 cycles of $95^{\circ} \mathrm{C}$ for $5 \mathrm{~s}$ and $60^{\circ} \mathrm{C}$ for 30 $\mathrm{s}$. The melting curves were generated to investigate the specificity of the PCR reaction. For the normalization of the gene levels, the level of $\beta$-actin was used to correct minor variations in the input RNA amount or inefficiencies in the reverse transcription. The relative quantification (RQ) of the expression of each gene was calculated according to comparative $\mathrm{Ct}$ method using this formula: $R Q=2^{-\Delta C t}$.

\section{Western blot analysis of CYP2E1}

Western blotting was used to assess the levels of the CYP2E1 protein in hepatic microsomes according to previously published methods ${ }^{[17]}$. Briefly, the microsomal proteins $(20 \mu \mathrm{g})$ in the hepatic microsomes were subjected to sodium dodecyl sulfate-polyacrylamide $(10 \%)$ gel electrophoresis and transferred to polyvinylidene fluoride membranes (Millipore Corporation, Billerica, MA, USA). The blots were blocked for $2 \mathrm{~h}$ in 5\% non-fat dry milk in Tris-buffered saline- $0.1 \%$ Tween 20 and then washed. The membranes were then incubated with the primary antibody (polyclonal rabbit antirat CYP2E1, 1:200 dilution) overnight at $4{ }^{\circ} \mathrm{C}$ followed by a horseradish peroxidase-conjugated secondary anti-rabbit antibody (1:5000 dilution) for $2 \mathrm{~h}$. The immunoreactivity was detected using a chemiluminescent substrate (Thermo Fisher Scientific Inc, Rockford, IL, USA) and a gel imaging system (Bio-Rad ChemiDoc XRS+ System, Hercules, CA, USA). The levels of CYP2E1 were normalized according to the reference bands of $\beta$-actin.

\section{Sample assays}

According to their different MS assay behaviors, six probes were divided into two administration groups and were observed by LC-MS. Midazolam, dextromethorphan, and omeprazole were scanned for their $[\mathrm{M}+\mathrm{H}]^{+}$using the scan mode of the mass spectrometer. They were measured simultaneously in our study, using a previously described assay ${ }^{[18]}$. The lowest limits of the quantitation of midazolam, dextromethorphan and omeprazole in rat plasma were $2.0 \mathrm{ng} / \mathrm{mL}$ with a good recovery (greater than $85 \%$ ) and good precision (less than 10\%). The linear range for these compounds was 2-2000 ng/mL. Theophylline, chlorzoxazone and diclofenac were scanned for their $[\mathrm{M}-\mathrm{H}]^{-}$. The simultaneous determination of the compounds was developed as follows: $10 \mu \mathrm{L}$ of chlorpropamide ( $2 \mu \mathrm{g} / \mathrm{mL}$, IS2) was added to $0.1 \mathrm{~mL}$ of plasma, then the mixture was extracted with $5 \mathrm{~mL}$ ethyl acetate after acidification with $100 \mu \mathrm{L}$ of $0.01 \mathrm{~mol} / \mathrm{L} \mathrm{HCl}$. The organic layer of $3.5 \mathrm{~mL}$ was transferred to a clean tube and evaporated to dryness. The residue was reconstituted in 200 $\mu \mathrm{L}$ of $0.1 \%$ ammonia and centrifuged at $20000 \times g$. A $5-\mu \mathrm{L}$ aliquot of the supernatant was injected into an ODS $\mathrm{C}_{18}(4.6$ $\mu \mathrm{m}, 150 \mathrm{~mm} \times 2.0 \mathrm{~mm}$ ID) column. The mobile phase consisted of 0.01\% $\mathrm{NH}_{4} \mathrm{Ac}$ :methanol=30:70 $(v / v)$ at a flow rate of 0.2 $\mathrm{mL} / \mathrm{min}$. The data collected by the mass spectrometer with the ESI probe was operated using the selected ion monitoring model in SIM. The resulting $m / z$ was 179.0 for theophylline, 167.95 for chlorzoxazone, 294.0 for diclofenac, and $m / z 275.0$ for chlorpropamide (IS2). The lowest limits of quantitation for theophylline, chlorzoxazone and diclofenac in rat plasma were $2.0,2.0$, and $50 \mathrm{ng} / \mathrm{mL}$, respectively with a good recovery (greater than $85 \%$ ) and good precision (less than 10\%). The linear ranges of theophylline and chlorzoxazone were 2-4000 $\mathrm{ng} / \mathrm{mL}$ and that of diclofenac was 50-4000 ng/mL.

In the incubation mixture, the 6-hydroxychlorzoxazone level was measured using HPLC. The incubation samples were centrifuged at $20000 \times g$ twice for $10 \mathrm{~min}$. Subsequently, the supernatant $(20 \mu \mathrm{L})$ was applied to the HPLC system (Shimadzu, Tokyo, Japan). The chromatographic separation of 6-hydroxychlorzoxazone was achieved using a Shimadzu Shim-pack VP-ODS $\mathrm{C}_{18}$ column $(150 \mathrm{~mm} \times 4.6 \mathrm{~mm}, 5 \mu \mathrm{m}$ particle size). The mobile phase consisted of water containing $0.05 \%(v / v)$ phosphoric acid and acetonitrile $(78: 22, v / v)$. The flow rate was $1.0 \mathrm{~mL} / \mathrm{min}$, and the analytical wavelength was $287 \mathrm{~nm}$. The linear range of 6-hydroxychlorzoxazone in the incubation mixture was $0.05-10.0 \mu \mathrm{g} / \mathrm{mL}$.

\section{Pharmacokinetic analyses}

The concentration-time data of the six probes for each rat were individually analyzed using noncompartmental analysis (Phoenix WinNonlin 6.1; Pharsight, St Louis, MO, USA). The enzyme kinetic parameters were estimated using non-linear least-squares regression and a programming solver (Microsoft Excel 2010). The Michaelis-Menten equation was used to cal- 
culate the apparent $K_{\mathrm{m}}$ and $V_{\max }$ values for single-enzyme systems. The Eadie-Hofstee plots were used to check for biphasic kinetics. If the Eadie-Hofstee plots indicated biphasic kinetics, the following equation was used to estimate the kinetic parameters for a two enzymes system:

$$
V=\frac{V_{\max , 1} S}{K_{m, 1}+S}+\frac{V_{\max , 2} S}{K_{m, 2}+S}
$$

where subscripts 1 and 2 denoted the high- and low-affinity enzymes of the reaction, respectively. $S$ is the concentration of chlorzoxazone. The intrinsic clearance $\left(\mathrm{Cl}_{\mathrm{int}, \mathrm{i}}\right)$ is defined as $V_{\text {max }, \mathrm{i}} / K_{\mathrm{m}, \mathrm{i}}$.

\section{Statistical analysis}

The data are presented as the mean \pm standard deviation (SD) values. The significant differences between groups were evaluated using the one-way analysis of variance. If the analysis results were significant, the differences between the groups were estimated using the Student-Newman-Keuls multiplecomparison test for post hoc analysis. A $P$ value of less than 0.05 was considered statistically significant.

\section{Results}

Effects of acute and chronic administration of caderofloxacin on the pharmacokinetic behaviors of the probes

The mean plasma concentration-time curves of the probes in the absence and presence of caderofloxacin were obtained. The results suggested that the co-administration of a single dose of caderofloxacin at $9 \mathrm{mg} / \mathrm{kg}$ via an oral application in rats did not change the pharmacokinetic profile of the six probes (Figure 1 and Table 1). After 14 consecutive days of the administration of caderofloxacin $(9 \mathrm{mg} / \mathrm{kg})$, the mean $\mathrm{AUC}_{0-\infty}$ value for chlorzoxazone in caderofloxacin-treated rats was significantly lower than that in control rats $(150.2 \pm 9.4 \mu \mathrm{g} \cdot \mathrm{h} / \mathrm{mL}$ in caderofloxacin-treated rats $v s 214.4 \pm 7.22 \mu \mathrm{g} \cdot \mathrm{h} / \mathrm{mL}$ in control rats), and the $t_{1 / 2}$ of chlorzoxazone in caderofloxacin-treated rats was significantly faster than that in control rats $(26.1 \pm 2.9$ min in caderofloxacin-treated rats $v s 31.8 \pm 2.7 \mathrm{~min}$ in control rats), indicating that the metabolism of chlorzoxazone may have increased (Figure 2 and Table 2). Furthermore, the chronic administration of caderofloxacin in rats resulted in a slightly increasing trend in the $\mathrm{AUC}_{0-\infty}$ of theophylline, but no significant difference was found.

\section{Effects of the chronic administration of caderofloxacin on the} pharmacokinetics of chlorzoxazone in rats

The cocktail approach for assessing the potential effects of caderofloxacin on the activities of hepatic CYP450 indicated that the chronic administration of caderofloxacin may induce CYP2E1, resulting in the increased metabolism of chlorzoxazone. To verify the above result, we designed an independent experiment to authenticate the effects of the chronic administration of caderofloxacin on the pharmacokinetics of chlorzoxazone in rats. Compared with control rats, chronic caderofloxacin-treated rats had lower plasma concentrations of chlorzoxazone, which resulted in lower exposure $\left(\mathrm{AUC}_{0-\infty}\right)$ (Figure 3). The mean $\mathrm{AUC}_{0-\infty}$ of chlorzoxazone in caderofloxacin-treated rats $(151.1 \pm 9.3 \mu \mathrm{g} \cdot \mathrm{h} / \mathrm{mL})$ was $74 \%$ of that in control rats $(204.5 \pm 14.3 \mu \mathrm{g} \cdot \mathrm{h} / \mathrm{mL})$, and the $\mathrm{Cl}$ of chlorzoxazone in caderofloxacin-treated rats $\left(6.62 \pm 0.17 \mathrm{~mL} / \mathrm{kg} \cdot \mathrm{min}^{-1}\right)$ was significantly higher than that in control rats $\left(4.91 \pm 0.32 \mathrm{~mL} / \mathrm{kg} \cdot \mathrm{min}^{-1}\right)$. However, the value of $t_{1 / 2}$ was not altered by caderofloxacin treatment $(27.3 \pm 1.7 \mathrm{~min}$ in caderofloxacin treated rats $v s$

Table 1. Main pharmacokinetic parameters of probes after intravenous administration of the cocktail solutions to rats in absence or presence of caderofloxacin. Caderofloxacin $(9 \mathrm{mg} / \mathrm{kg}$ ) was given once via intragastrical administration $15 \mathrm{~min}$ ahead of the cocktail solutions. Data are expressed as mean $\pm \operatorname{SD}(n=6)$.

\begin{tabular}{|c|c|c|c|}
\hline \multirow[t]{2}{*}{ Midazolam } & $t_{1 / 2}(\min )$ & $25.3 \pm 5.1$ & $30.7 \pm 3.3$ \\
\hline & $\mathrm{Cl}\left(\mathrm{mL} / \mathrm{kg} \cdot \mathrm{min}^{-1}\right)$ & $58.0 \pm 5.6$ & $65.7 \pm 29.1$ \\
\hline \multirow[t]{2}{*}{ Dextromethorphan } & $t_{1 / 2}(\min )$ & $99.1 \pm 6.4$ & $110.7 \pm 14.5$ \\
\hline & $\mathrm{AUC}_{0-\infty}(\mathrm{ng} \cdot \mathrm{min} / \mathrm{mL})$ & $38299.0 \pm 2839.5$ & $35369.4 \pm 7947.1$ \\
\hline & $A \cup C_{0-\infty}(n g \cdot m i n / m L)$ & $46715.8 \pm 2816.7$ & $49691.6 \pm 3009.5$ \\
\hline & $\mathrm{Cl}\left(\mathrm{mL} / \mathrm{kg} \cdot \mathrm{min}^{-1}\right)$ & $42.9 \pm 2.6$ & $40.4 \pm 2.4$ \\
\hline \multirow[t]{3}{*}{ Theophylline } & $t_{1 / 2}(\min )$ & $100.6 \pm 2.0$ & $123.2 \pm 25.8$ \\
\hline & $A \cup C_{0-\infty}(n g \cdot m i n / m L)$ & $285172.9 \pm 40807.1$ & $279491.3 \pm 19773.6$ \\
\hline & $\mathrm{Cl}\left(\mathrm{mL} / \mathrm{kg} \cdot \mathrm{min}^{-1}\right)$ & $3.6 \pm 0.5$ & $3.6 \pm 0.3$ \\
\hline & $A \cup C_{0-\infty}(n g \cdot m i n / m L)$ & $47554.8 \pm 7358.5$ & $46399.8 \pm 7831.5$ \\
\hline & $\mathrm{Cl}\left(\mathrm{mL} / \mathrm{kg} \cdot \mathrm{min}^{-1}\right)$ & $10.7 \pm 1.7$ & $11.0 \pm 1.6$ \\
\hline
\end{tabular}



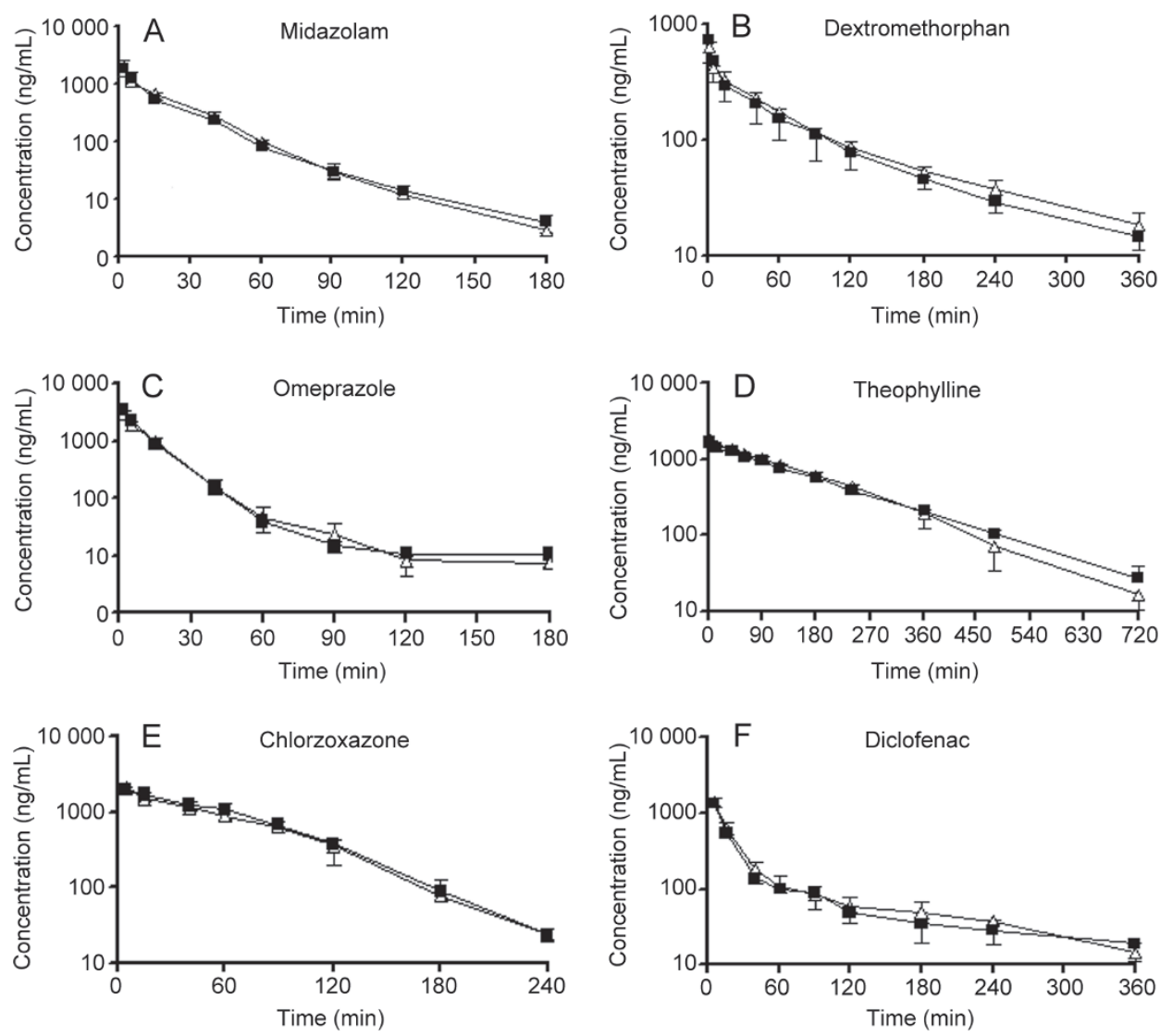

Figure 1. The mean plasma concentration-time curves of (A) midazolam (2 mg/kg), (B) dextromethorphan (5 mg/kg), (C) omeprazole (2 mg/kg), (D) theophylline (1 mg/kg), (E) chlorzoxazone (1 mg/kg) and $(F)$ diclofenac $(0.5 \mathrm{mg} / \mathrm{kg})$ after intravenous administration of the cocktail solutions to rats in the absence (open triangle) or presence (solid square) of caderofloxacin. Caderofloxacin $(9 \mathrm{mg} / \mathrm{kg}$ ) was given once via an intragastrical administration $15 \mathrm{~min}$ ahead of the cocktail solutions. The data are expressed as the mean $\pm \operatorname{SD}(n=6)$.

Table 2. Main pharmacokinetic parameters of probes after intravenous administration of the cocktail solutions to rats in absence or presence of caderofloxacin. Caderofloxacin $(9 \mathrm{mg} / \mathrm{kg}$ ) was given via intragastrical administration twice daily for $14 \mathrm{~d}$. Data are expressed as mean $\pm S D(n=6)$. ${ }^{\mathrm{b}} P<0.05,{ }^{\mathrm{c}} P<0.01$ vs absence of caderofloxacin.

\begin{tabular}{|c|c|c|c|}
\hline Probes & PK parameters & In absence & In presence \\
\hline \multirow[t]{2}{*}{ Midazolam } & $t_{1 / 2}(\min )$ & $28.7 \pm 4.4$ & $30.1 \pm 7.1$ \\
\hline & $\mathrm{AUC}_{0-\infty}(\mathrm{ng} \cdot \mathrm{min} / \mathrm{mL})$ & $25494.4 \pm 7951.2$ & $27977.3 \pm 2916.3$ \\
\hline \multirow[t]{2}{*}{ Dextromethorphan } & $t_{1 / 2}(\min )$ & $108.2 \pm 24.3$ & $98.3 \pm 25.4$ \\
\hline & $\mathrm{AUC}_{0-\infty}(\mathrm{ng} \cdot \mathrm{min} / \mathrm{mL})$ & $34757.7 \pm 4177.4$ & $34626.1 \pm 4269.7$ \\
\hline & $\mathrm{AUC}_{0-\infty}(\mathrm{ng} \cdot \mathrm{min} / \mathrm{mL})$ & $50318.5 \pm 6382.5$ & $46229.7 \pm 4795.5$ \\
\hline & $\mathrm{Cl}\left(\mathrm{mL} / \mathrm{kg} \cdot \mathrm{min}^{-1}\right)$ & $40.0 \pm 4.9$ & $43.2 \pm 4.8$ \\
\hline \multirow[t]{3}{*}{ Theophylline } & $t_{1 / 2}(\min )$ & $100.0 \pm 8.6$ & $96.5 \pm 11.7$ \\
\hline & $\mathrm{AUC}_{0-\infty}($ ng.min/mL) & $271091.3 \pm 18400.4$ & $306709.9 \pm 34714.5$ \\
\hline & $\mathrm{Cl}\left(\mathrm{mL} / \mathrm{kg} \cdot \mathrm{min}^{-1}\right)$ & $3.7 \pm 0.2$ & $3.3 \pm 0.3^{b}$ \\
\hline Chlorzoxazone & $t_{1 / 2}(\min )$ & $31.8 \pm 2.7$ & $26.1 \pm 2.9^{b}$ \\
\hline & $\mathrm{AUC}_{0-\infty}(\mu \mathrm{g} \cdot \mathrm{min} / \mathrm{mL})$ & $50546.2 \pm 7843.4$ & $51500.1 \pm 9464.3$ \\
\hline & $\mathrm{Cl}\left(\mathrm{mL} / \mathrm{kg} \cdot \mathrm{min}^{-1}\right)$ & $9.5 \pm 1.7$ & $9.5 \pm 1.5$ \\
\hline
\end{tabular}



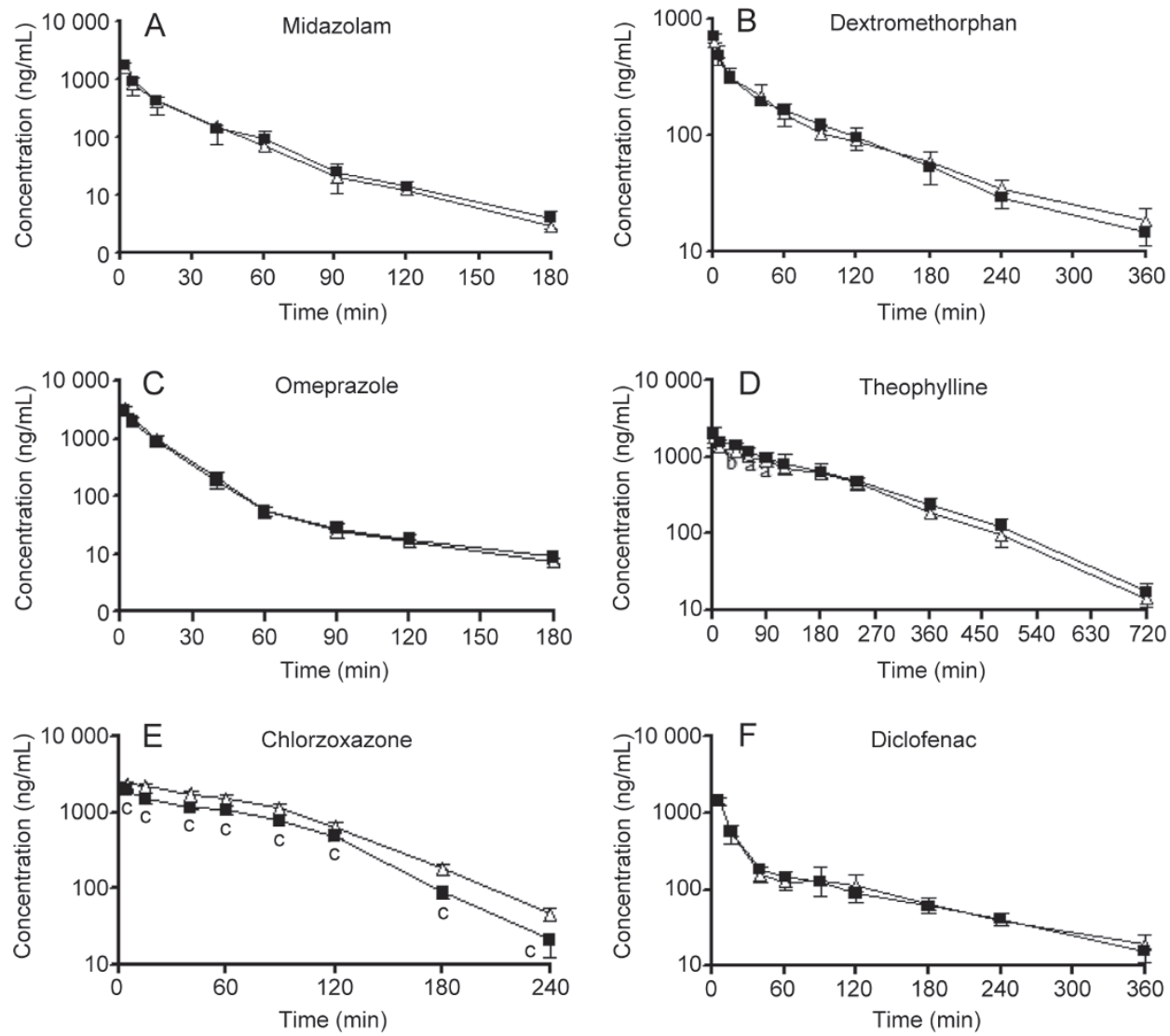

Figure 2. The mean plasma concentration-time curves of (A) midazolam (2 mg/kg), (B) dextromethorphan (5 mg/kg), (C) omeprazole (2 mg/kg), (D) theophylline (1 mg/kg), (E) chlorzoxazone $(1 \mathrm{mg} / \mathrm{kg})$ and $(F)$ diclofenac $(0.5 \mathrm{mg} / \mathrm{kg})$ after the intravenous administration of the cocktail solutions to rats in the absence (open triangle) or presence (solid square) of caderofloxacin. Caderofloxacin $(9 \mathrm{mg} / \mathrm{kg}$ ) was given via an intragastrical administration twice daily for $14 \mathrm{~d}$. The data are expressed as the mean $\pm \mathrm{SD}(n=6) .{ }^{\mathrm{b}} P<0.05,{ }^{\mathrm{c}} P<0.01 \mathrm{vs}$ in the absence of caderofloxacin.

$29.8 \pm 3.1 \mathrm{~min}$ in control rats). The results also suggested that chronic caderofloxacin treatment may significantly increase the enzyme activities of CYP2E1.

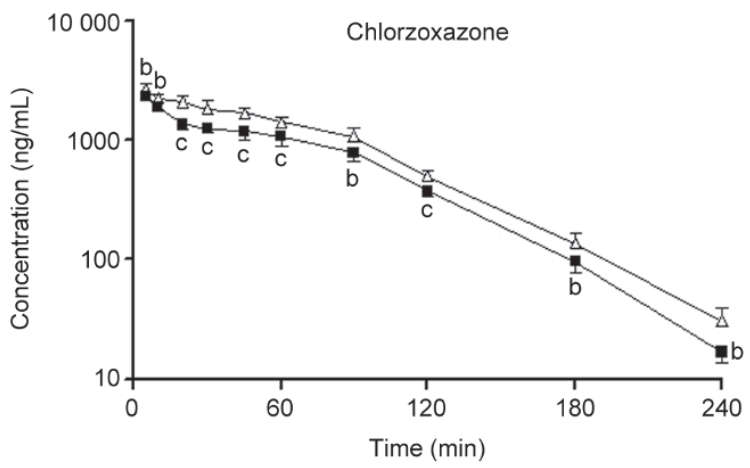

Figure 3. The mean plasma concentration-time curves of chlorzoxazone after the intravenous administration of $1 \mathrm{mg} / \mathrm{kg}$ of chlorzoxazone to control (open triangle) and caderofloxacin-treated (solid square) rats. Caderofloxacin $(9 \mathrm{mg} / \mathrm{kg}$ ) was given via an intragastrical administration twice daily for $14 \mathrm{~d}$. The data are expressed as the mean \pm SD $(n=6)$. ${ }^{\mathrm{b}} P<0.05,{ }^{\mathrm{c}} P<0.01$ vs in the absence of caderofloxacin.
Metabolism of chlorzoxazone in hepatic microsomes of caderofloxacin-treated rats

To further confirm our in vivo results, metabolism of chlorzoxazone was measured in caderofloxacin-treated rat hepatic microsomes using the formation of the chlorzoxazone metabolite 6-hydroxychlorzoxazone. The formation rates of 6-hydroxychlorzoxazone in rat liver microsomes (Figure 4A) were obtained, and the corresponding kinetic parameters are

Table 3. Kinetic parameters for formation of 6-hydroxychlorzoxazone in hepatic microsomes of control and caderofloxacin-treated rats. Caderofloxacin $(9 \mathrm{mg} / \mathrm{kg}$ ) was given via intragastrical administration twice daily for $14 \mathrm{~d}$. Data are expressed as mean \pm SD $(n=4) .{ }^{b} P<0.05,{ }^{c} P<0.01$ vs control rats.

\begin{tabular}{lcc}
\hline \multicolumn{1}{c}{ Parameters } & Control & Caderofloxacin treatment \\
\hline$K_{\mathrm{m}, 1}(\mu \mathrm{mol} / \mathrm{L})$ & $45.61 \pm 13.64$ & $53.68 \pm 5.56$ \\
$V_{\max , 1}\left(\mu \mathrm{mol} \cdot \mathrm{min}^{-1} \cdot \mathrm{g}^{-1}\right)$ & $0.29 \pm 0.04$ & $0.35 \pm 0.04$ \\
$V_{\max , 1} / K_{\mathrm{m} 1}\left(\mathrm{~mL} \cdot \mathrm{min}^{-1} \cdot \mathrm{g}^{-1}\right)$ & $6.63 \pm 1.06$ & $6.47 \pm 0.81$ \\
$K_{\mathrm{m}, 2}(\mu \mathrm{mol} / \mathrm{L})$ & $838.18 \pm 48.76$ & $934.23 \pm 10.58^{\mathrm{b}}$ \\
$V_{\max , 2}\left(\mu \mathrm{mol} \cdot \mathrm{min}^{-1} \cdot \mathrm{g}^{-1}\right)$ & $2.02 \pm 0.10$ & $2.64 \pm 0.09^{\mathrm{c}}$ \\
$V_{\max , 2} / K_{\mathrm{m} 2}\left(\mathrm{~mL} \cdot \mathrm{min}^{-1} \cdot \mathrm{g}^{-1}\right)$ & $2.42 \pm 0.03$ & $2.83 \pm 0.07^{\mathrm{c}}$ \\
\hline
\end{tabular}



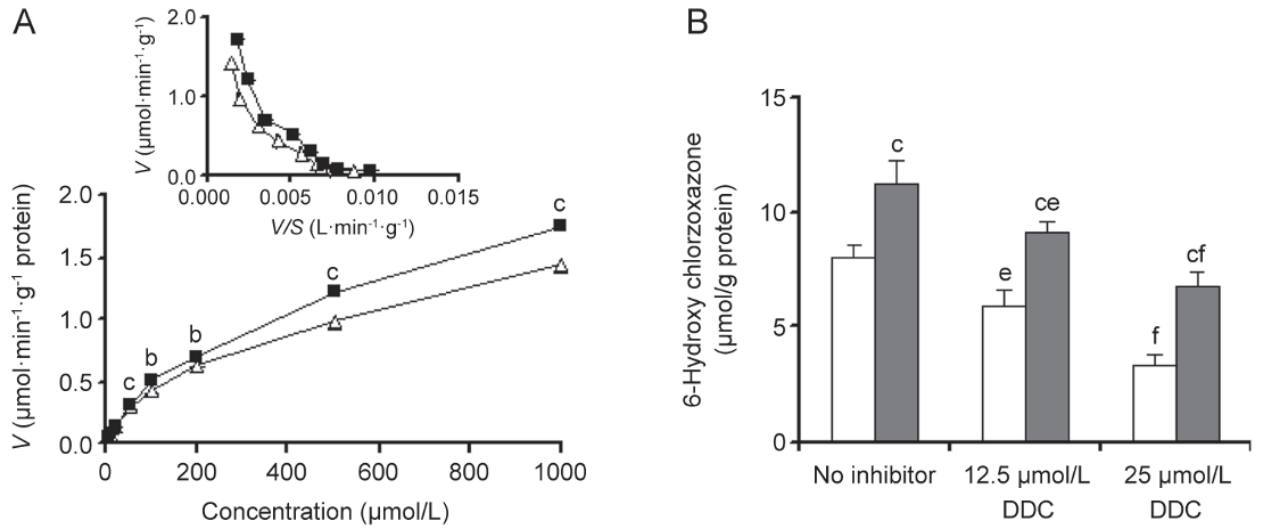

Figure 4. (A) The formation of 6-hydroxychlorzoxazone in the hepatic microsomes of control (open triangle) and caderofloxacin-treated (solid square) rats. Insets represent the corresponding Eadie-Hofstee plots. (B) The effects of diethyldithiocarbamate (DDC, a CYP2E1 inhibitor) on the formation of 6-hydroxychlorzoxazone in the hepatic microsomes of control (white bar) and caderofloxacin-treated (shaded bar) rats. Caderofloxacin (9 mg/kg) was given via an intragastrical administration twice daily for $14 \mathrm{~d}$. The data are expressed as the mean \pm SD $(n=4)$. ${ }^{b} P<0.05,{ }^{c} P<0.01$ vs control rats. ${ }^{\mathrm{e}} P<0.05,{ }^{\mathrm{f}} P<0.01$ vs without inhibitor.

summarized in Table 3. It is notable that the hepatic metabolism of chlorzoxazone showed biphasic kinetic characteristics, suggesting the involvement of two different enzymes. The apparent $K_{\mathrm{m}, 1}$ value (high-affinity component) was approximately $45.61 \mu \mathrm{mol} / \mathrm{L}$, whereas the $K_{\mathrm{m}, 2}$ value (low-affinity component) was $838.18 \mu \mathrm{mol} / \mathrm{L}$ in the liver microsomes of control rats. The apparent maximum velocity $\left(V_{\max , 2}\right)$ for the low-affinity component was faster than that $\left(V_{\max , 1}\right)$ for the high-affinity component, but the intrinsic clearance $\left(V_{\max , 2}\right)$ $\left.K_{\mathrm{m}, 2}\right)$ of the low-affinity component was significantly lower than that $\left(V_{\max , 1} / K_{\mathrm{m}, 1}\right)$ for the high-affinity component (Table $3)$. The fourteen-day caderofloxacin treatment significantly increased the formation of 6-hydroxychlorzoxazone in hepatic microsomes and resulted in an increase in the intrinsic clearance of the low-affinity component.

Effects of diethyldithiocarbamate on chlorzoxazone metabolism in caderofloxacin-treated hepatic microsomes

To verify the role of CYP2E1 in chlorzoxazone metabolism, the formation rates of 6-hydroxychlorzoxazone in rat hepatic microsomes were investigated in the presence of a chemical inhibitor, DDC. The results showed that DDC inhibited chlorzoxazone metabolism in a dose-dependent manner (Figure 4B) in hepatic microsomes from caderofloxacin-treated and control rats. In comparison with the absence of DDC, the addition of $25 \mu \mathrm{mol} / \mathrm{L}$ DDC significantly decreased the generation of 6-hydroxychlorzoxazone in the hepatic microsomes of control and caderofloxacin-treated rats. For the control and caderofloxacin-treated rats, the generation of 6-hydroxychlorzoxazone was $41 \%$ and $60 \%$ of that in the groups without DDC, respectively. The inhibitory effect of DDC in the microsomes of control rats was much stronger than that in the microsomes of caderofloxacin-treated rats. These results indicated that CYP2E1 is a major metabolic enzyme in chlorzoxazone depletion and chlorzoxazone metabolism could be inhibited by the CYP2E1 inhibitor DDC. The results also verified the role of
CYP2E1 in chlorzoxazone metabolism in rats, which indicates that the increase in chlorzoxazone metabolism in caderofloxacin-treated rats was partly attributable to the induction of CYP2E1 activity by chronic caderofloxacin administration.

\section{QT-PCR and Western blotting}

The mRNA levels of CYP2E1 in the hepatic microsomes of control and caderofloxacin-treated rats were measured using QT-PCR (Figure 5A). Chronic caderofloxacin administration significantly enhanced the expression of hepatic CYP2E1 mRNA, inducing a 1.6-fold increase compared with that of control rats. The up-regulation of the mRNA level of CYP2E1 in the hepatic microsomes of caderofloxacin-treated rats was in parallel with the elevation of CYP2E1 activity, resulting in an increase in chlorzoxazone metabolism.

The levels of the CYP2E1 protein in the hepatic microsomes from control and caderofloxacin-treated rats were assessed with Western blotting (Figure 5B). The level of CYP2E1 in the hepatic microsomes of caderofloxacin-treated rats was significantly higher than that in the microsomes from control rats, $190 \%$ of that in control rats, which suggests an up-regulation of CYP2E1 expression. The increased expression of CYP2E1 in the hepatic microsomes of caderofloxacin-treated rats was in parallel with the elevation of 6-hydroxychlorzoxazone production, which indicates that the enhancement of CYP2E1 expression in the hepatic microsomes induced by the chronic administration of caderofloxacin contributed to the increase in the metabolism of chlorzoxazone.

\section{Discussion}

An assessment of the enzyme activity of CYP450 is essential for characterizing the phase I metabolism of biological systems or to evaluate the inhibition/induction properties of xenobiotics. The most common use of the cocktail approach to date has been in the evaluation of the potential of drug-drug interactions with a new drug ${ }^{[19]}$. Because information on multiple 
A

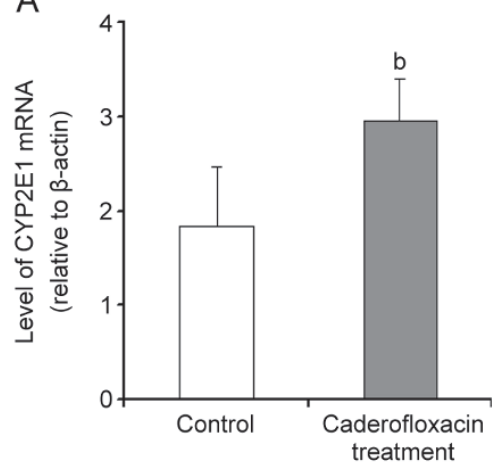

B

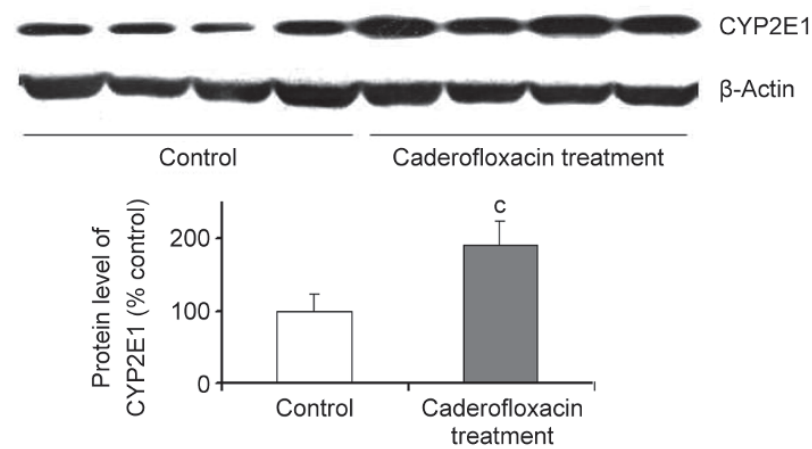

Figure 5. The expression of (A) the mRNA levels and (B) the protein levels of CYP2E1 in the hepatic microsomes of control (white bar) and caderofloxacin-treated (shaded bar) rats. Caderofloxacin $(9 \mathrm{mg} / \mathrm{kg}$ ) was given via an intragastrical administration twice daily for $14 \mathrm{~d}$. The data are expressed as the mean \pm SD $(n=4)$. ${ }^{b} P<0.05,{ }^{c} P<0.01$ vs control rats.

pathways can be obtained in a single study, the cocktail strategy provides an efficient means by which to screen for potential drug interactions ${ }^{[20]}$. For example, the cocktail approach has recently been used to evaluate the potential for new developing drugs to alter CYP enzyme activity ${ }^{[21,22]}$. We evaluated the potential effects of the acute and chronic administration of caderofloxacin on hepatic cytochrome P450 activity using the cocktail approach. The results indicated that only chronic caderofloxacin administration induced CYP2E1 activity, causing a significant decrease in AUC and $t_{1 / 2}$ of chlorzoxazone and a distinct increase in $\mathrm{Cl}$. The phenomenon also indicated that caderofloxacin may be an inducer of CYP2E1 and the chronic administration of caderofloxacin may raise CYP2E1 levels, resulting in the increased metabolism of chlorzoxazone.

When a cocktail approach is used, it is important to overcome the problem of potential drug-drug interactions between the various substrates. The probability of such interactions may be overcome by the simultaneous administration of low dosages of the validated probe drugs in a tailored cocktail approach, providing information on several metabolic pathways in a single experimental session ${ }^{[23,24]}$. However, the results obtained from the mixed probe administration still need to be confirmed by the individual administration of each specific probe of the CYPs in an independent study. Thus, we designed an experiment to verify the pharmacokinetic drug interaction between caderofloxacin and chlorzoxazone. The results indicated that the metabolism of chlorzoxazone in chronically caderofloxacin-treated rats had evidently increased and caderofloxacin had the potential to elevate rat hepatic CYP2E1 activity in vivo. It was interesting to find that caderofloxacin treatment increased the clearance of chlorzoxazone in rats, but its half-life was not significantly changed. This phenomenon may be due to the involvement of two enzymes in the metabolism of chlorzoxazone, a high-affinity component and a low-affinity component. It was found that the intrinsic clearance of the low-affinity component $\left(V_{\max , 2} / K_{\mathrm{m}, 2}\right)$ in caderofloxacin-treated rats was significantly higher than that in control rats. However, the chronic caderofloxacin treatment did not affect the intrinsic clearance of the high-affinity component
$\left(V_{\max , 1} / K_{\mathrm{m}, 1}\right)$. The low-affinity component is responsible for the metabolism of high concentrations of chlorzoxazone, while the high-affinity component is in charge of the metabolism of low concentrations of chlorzoxazone, which results in the increased clearance and unchanged half-life of chlorzoxazone in caderofloxacin-treated rats.

The in vitro microsomal study demonstrated that CYP2E1 is a major metabolic enzyme involved in chlorzoxazone metabolism in rats and a fourteen-day caderofloxacin treatment significantly increased the activity of CYP2E1 in hepatic microsomes, leading to the increased formation of 6-hydroxychlorzoxazone in the hepatic microsomes of caderofloxacintreated rats. Furthermore, the study results from QT-PCR and Western blot analysis also showed that chronic caderofloxacin treatment induced the mRNA and protein expression of CYP2E1, which were consistent with the pharmacokinetic results.

CYP2E1 catalyzes the biotransformation of almost $2 \%$ of all clinically used drugs in humans ${ }^{[25]}$. Rat CYP2E1 is a homolog of human CYP2E1 and is expressed in many tissues, including the liver ${ }^{[26]}$. CYP2E1 is a classic ethanol-inducible CYP and has been extensively studied because it catalyzes the metabolism of drugs, such as acetaminophen, chlorzoxazone, and halothane, and endogenous substrates, such as arachidonic acid, fatty acids, gluconeogenic precursors and estrogenic metabolites. It also bioactivates several procarcinogens and protoxins, including $\mathrm{N}$-nitrosodimethylamine, benzene, and carbon tetrachloride, to their reactive intermediates ${ }^{[27]}$. CYP2E1 generates reactive oxygen species (ROS) and substrate-derived radicals, such as oxygen and hydroxyl radicals, which can mediate lipid peroxidation, protein inactivation and DNA damage, leading to cellular injury, especially in the presence of CYP2E1 induc$\mathrm{ers}^{[28]}$. Several clinical disorders are associated with changes in the regulation of CYP2E1 and its consequent abnormalities, which include alcoholic liver disease, carcinogenesis, hepatocellular and cholestatic injury, among others ${ }^{[29]}$. Some drugs exert their hepatotoxic effects through the involvement of CYP2E1. For examples, furan is metabolized by CYP2E1 to a toxic metabolite, cis-2-butene-1,4-dial, that may interact with 
proteins to cause cytotoxicity or react with nucleosides to form substituted deoxyguanosine adducts ${ }^{[30]}$. Tetrandrine promotes mitochondrial dysfunction in hepatocytes through the generation of ROS induced by CYP2E1 ${ }^{[31]}$. Hepatic injury induced by the metabolism of acetaminophen ( $N$-acetyl- $p$-benzoquinone imine) is usually mediated by an increase in CYP2E1 activity and enhanced ROS generation via the direct activation of the JNK-dependent cell death pathway ${ }^{[32]}$.

In the present study, after the treatment of rats for $14 \mathrm{~d}$ with caderofloxacin, both the enzyme activity and the protein and mRNA expression levels of CYP2E1 were significantly increased when a dose of $9 \mathrm{mg} / \mathrm{kg}$ was administered. We observed a significant decrease in the chlorzoxazone level in rats after the chronic administration of caderofloxacin, indicating that caderofloxacin may induce the expression of CYP2E1 in vivo. The mRNA and protein expression results agreed with the pharmacokinetic results, which seemed consistent with a previous report. This report found that the chronic administration of ciprofloxacin could cause the up-regulation of CYP2E1 in mouse microsomes using Western blot analysis $^{[33]}$. Recent clinical investigation has indicated a significant association between ciprofloxacin use and an increased risk of hepatotoxicity ${ }^{[34,35]}$. This hepatotoxicity has resulted from the induction of the drug metabolizing enzyme CYP2E1 by the administration of ciprofloxacin. Because caderofloxacin is a newly developed active quinolone derivatized from ciprofloxacin, more attention should be paid to the liver injury induced by caderofloxacin in its future clinical use. In addition, CYP2E1 is involved in the diverse oxidative metabolism of a wide spectrum of endogenous compounds as well as xenobiotics, including procarcinogens, such as benzene ${ }^{[36]}$ and the commonly recognized hepatocarcinogen, caderofloxacin. This may lead to the accumulation of carcinogenic metabolites in vivo, and it is possibly harmful to the human body when it is used in long term. Furthermore, caderofloxacin is used in combination with other drugs metabolized by CYP2E1, and more attention should be paid to the potential drug-drug interactions to reduce adverse reactions or the failure in treatment due to low plasma concentration.

It has been considered clinically important to focus on the potential interaction between theophylline and new quinolone antimicrobial agents ${ }^{[37]}$. Accumulating evidence has shown that CYP1A2 is the major enzyme responsible for theophylline metabolism ${ }^{[38]}$. The concomitant administration of drugs that can inhibit this enzyme may predispose patients to theophylline toxicity. A series of fluoroquinolones, including enoxacin, ciprofloxacin, tosufloxacin, clinafloxacin, grepafloxacin, pefloxacin and antofloxacin, have been reported to interfere with theophylline metabolism by inhibiting CYP1A2 activity ${ }^{[39]}$. For example, ciprofloxacin causes a decrease (30\%) in the total body clearance of theophylline, which results in a series of clinical signs and symptoms of theophylline toxicity ${ }^{[40]}$. Consequently, it is important to evaluate the potential risk of caderofloxacin, which may decrease the metabolism of theophylline through its inhibition of the activity of CYP1A2. However, the results indicate that the acute or chronic administration of caderofloxacin did not change the activity of CYP1A2. This finding agrees with a previous study, which reported that caderofloxacin is a negligible inhibitor of CYP1A2 in human microsomes $^{[41]}$.

In conclusion, the activity of hepatic CYP2E1 increased as a result of the elevated mRNA and protein levels of hepatic CYP2E1 induced by the chronic administration of caderofloxacin. The co-administration of caderofloxacin should be considered a potential drug-drug interaction mediated by the induction of CYP2E1.

\section{Acknowledgements}

The project was supported by the National Natural Science Foundation of China (№ 81473273, 81373482 and 81573490), the Fundamental Research Funds for the Central Universities (No 2015PT042, ZD2014YX0026, and PT2014YX0057) and the Priority Academic Program for Development of the Jiangsu Higher Education Institutions.

\section{Author contribution}

Li LIU and Xiao-dong LIU designed the experiments and analyzed the data; Li LIU wrote the paper; Xiao-dong LIU revised the paper; Ming-xing MIAO, Ze-yu ZHONG, Ping XU and Yang CHEN performed the research.

\section{References}

1 Biedenbach DJ, Sutton LD, Jones RN. Antimicrobial activity of CS-940, a new trifluorinated quinolone. Antimicrob Agents Chemother 1995; 39: 2325-30.

2 Masuda N, Takahashi Y, Otsuki M, Ibuki E, Miyoshi H, Nishino T. In vitro and in vivo antibacterial activities of CS-940, a new 6-fluoro-8difluoromethoxy quinolone. Antimicrob Agents Chemother 1996; 40: 1201-7.

3 Miyazaki S, Domon H, Tateda K, Ohno A, Ishii Y, Matsumoto T, et al. In vitro and in vivo antibacterial activities of CS-940, a new fluoroquinolone, against isolates from patients with respiratory infections. Antimicrob Agents Chemother 1997; 41: 2582-5.

4 Spaggiari D, Geiser L, Daali Y, Rudaz S. Phenotyping of CYP450 in human liver microsomes using the cocktail approach. Anal Bioanal Chem 2014; 406: 4875-87.

5 Reginald FF. Probing the world of cytochrome P450 enzymes. Mol Interv 2004; 4: 157-62.

6 Youdim KA, Saunders KC. A review of LC-MS techniques and highthroughput approaches used to investigate drug metabolism bycytoc hrome P450s. J Chromatogr B Analyt Technol Biomed Life Sci 2010; 878: 1326-36.

7 Tanaka S, Uchida S, Inui N, Takeuchi K, Watanabe H, Namiki N. Simultaneous LC-MS/MS analysis of the plasma concentrations of a cocktail of 5 cytochrome P450 substrate drugs and their metabolites. Biol Pharm Bull 2014; 37: 18-25.

8 Ghassabian S, Chetty M, Tattam BN, Chem MC, Glen J, Rahme J, et al. A high-throughput assay using liquid chromatography-tandem mass spectrometry for simultaneous in vivo phenotyping of 5 major cytochrome p450 enzymes in patients. Ther Drug Monit 2009; 31: 239-46.

9 Ryu JY, Song IS, Sunwoo YE, Shon JH, Liu KH, Cha IJ, et al. Development of the "Inje cocktail" for high-throughput evaluation of five human cytochrome P450 isoforms in vivo. Clin Pharmacol 
Ther 2007; 82: 531-40.

10 Turpault S, Brian W, Van Horn R, Santoni A, Poitiers F, Donazzolo Y, et al. Pharmacokinetic assessment of a five-probe cocktail for CYPs 1A2, 2C9, 2C19, 2D6 and 3A. Br J Clin Pharmacol 2009; 68: 92835.

11 Jenkins J, Williams D, Deng Y, Collins DA, Kitchen VS. Eltrombopag, an oral thrombopoietin receptor agonist, has no impact on the pharmacokinetic profile of probe drugs for cytochrome P450 isoenzymes CYP3A4, CYP1A2, CYP2C9 and CYP2C19 in healthy men: a cocktail analysis. Eur J Clin Pharmacol 2010; 66: 67-76.

12 Yeh RF, Gaver VE, Patterson KB, Rezk NL, Baxter-Meheux F, Blake MJ, et al. Lopinavir/ritonavir induces the hepatic activity of cytochrome P450 enzymes CYP2C9, CYP2C19, and CYP1A2 but inhibits the hepatic and intestinal activity of CYP3A as measured by a phenotyping drug cocktail in healthy volunteers. J Acquir Immune Defic Syndr 2006; 42: 52-60.

13 Testa B, Pedretti A, Vistoli G. Reactions and enzymes in the metabolism of drugs and other xenobiotics. Drug Discov Today 2012; 17: 549-60.

14 Huang SM, Temple R, Throckmorton DC, Lesko L. Drug interaction studies: study design, data analysis, and implications for dosing and labeling. Clin Pharmacol Ther 2007; 81: 298-304.

15 Liu H, Liu L, Li J, Mei D, Duan R, Hu N, et al. Combined contributions of impaired hepatic CYP2C11 and intestinal breast cancer resistance protein activities and expression to increased oral glibenclamide exposure in rats with streptozotocin-induced diabetes mellitus. Drug Metab Dispos 2012; 40: 1104-12.

16 Li X, Wang X, Li Y, Zhu J, Su X, Yao X, et al. The activity, protein, and mrna expression of CYP2E1 and CYP3A1 in rats after exposure to acute and chronichigh altitude hypoxia. High Alt Med Biol 2014; 15 : 491-6.

17 Valencia-Olvera AC, Morán J, Camacho-Carranza R, Prospéro-García $\mathrm{O}$, Espinosa-Aguirre JJ. CYP2E1 induction leads to oxidative stress and cytotoxicity in glutathione-depleted cerebellar granule neurons. Toxicol In Vitro 2014; 28: 1206-14.

18 Xu X, Liu HY, Liu L, Xie L, Liu XD. The influence of a newly developed quinolone: antofloxacin, on CYP activity in rats. Eur J Drug Metab Pharmacokinet 2008; 33: 1-7.

19 Fuhr U, Jetter A, Kirchheiner J. Appropriate phenotyping procedures for drug metabolizing enzymes and transporters in humans and their simultaneous use in the "cocktail" approach. Clin Pharmacol Ther 2007; 81: 270-83.

20 Spaggiari D, Geiser L, Daali Y, Rudaz S. A cocktail approach for assessing the in vitro activity of human cytochrome P450s: An overview of current methodologies. J Pharm Biomed Anal 2014; S0731-7085: 00145-9.

21 Nordmark A, Andersson A, Baranczewski P, Wanag E, Ståhle L. Assessment of interaction potential of AZD2066 using in vitro metabolism tools, physiologically based pharmacokinetic modelling and in vivo cocktail data. Eur J Clin Pharmacol 2014; 70: 167-78.

22 Snyder BD, Rowland A, Polasek TM, Miners JO, Doogue MP. Evaluation of felodipine as a potential perpetrator of pharmacokinetic drug-drug interactions. Eur J Clin Pharmacol 2014; 70: 1115-22.

23 Bosilkovska M, Déglon J, Samer C, Walder B, Desmeules J, Staub C, et al. Simultaneous LC-MS/MS quantification of P-glycoprotein and cytochrome $\mathrm{P} 450$ probe substrates and their metabolites in DBS and plasma. Bioanalysis 2014; 6: 151-64.

24 Tomalik-Scharte D, Jetter A, Kinzig-Schippers M, Skott A, Sörgel F,
Klaassen T, et al. Effect of propiverine on cytochrome P450 enzymes: a cocktail interaction study in healthy volunteers. Drug Metab Dispos. 2005; 33: 1859-66.

25 Zuber R, Anzenbacherová E, Anzenbacher P. Cytochromes P450 and experimental models of drug metabolism. J Cell Mol Med 2002; 6: 189-98.

26 Martignoni M, Groothuis GM, de Kanter R. Species differences between mouse, rat, dog, monkey and human CYP-mediated drug metabolism, inhibition and induction. Expert Opin Drug Metab Toxicol 2006; 2: 875-94.

27 Joshi M, Tyndale RF. Regional and cellular distribution of CYP2E1 in monkey brain and its inductionby chronic nicotine. Neuropharmacology 2006; 50: 568-75.

28 Yan J, He X, Feng S, Zhai Y, Ma Y, Liang S, et al. Up-regulation on cytochromes $\mathrm{P} 450$ in rat mediated by total alkaloid extract from Corydalis yanhusuo. BMC Complement Altern Med 2014; 14: 306.

29 Dey A. Cytochrome P450 2E1: its clinical aspects and a brief perspective on the current research scenario. Subcell Biochem 2013; 67: 1-104.

30 Neuwirth C, Mosesso P, Pepe G, Fiore M, Malfatti M, Turteltaub K, et al. Furan carcinogenicity: DNA binding and genotoxicity of furan in rats in vivo. Mol Nutr Food Res 2012; 56: 1363-74.

31 Qi XM, Miao LL, Cai Y, Gong LK, Ren J. ROS generated by CYP450, especially CYP2E1, mediate mitochondrial dysfunction induced by tetrandrine in rat hepatocytes. Acta Pharmacol Sin 2013; 34: 122936.

32 Das J, Ghosh J, Manna P, Sil PC. Acetaminophen induced acute liver failure via oxidative stress and JNK activation: protective role of taurine by the suppression of cytochrome P450 2E1. Free Radic Res 2010; 44: 340-55.

33 Peterson TC, Peterson MR, Wornell PA, Blanchard MG, Gonzalez FJ. Role of CYP1A2 and CYP2E1 in the pentoxifylline ciprofloxacin drug interaction. Biochem Pharmacol 2004; 68: 395-402.

34 Alshammari TM, Larrat EP, Morrill HJ, Caffrey AR, Quilliam BJ, LaPlante KL. Risk of hepatotoxicity associated with fluoroquinolones: a national case-control safety study. Am J Health Syst Pharm 2014; 71: 37-43.

35 Orman ES, Conjeevaram HS, Vuppalanchi R, Freston JW, Rochon J, Kleiner DE, et al. Clinical and histopathologic features of fluoroquinolone-induced liver injury. Clin Gastroenterol Hepatol 2011; 9: 517-523.e3.

36 Arinç E, Arslan S, Bozcaarmutlu A, Adali O. Effects of diabetes on rabbit kidney and lung CYP2E1 and CYP2B4 expression and drug metabolism and potentiation of carcinogenic activity of $\mathrm{N}$-nitrosodimethylamine in kidney and lung. Food Chem Toxicol 2007; 45: 107-18.

37 Hines LE, Murphy JE. Potentially harmful drug-drug interactions in the elderly: a review. Am J Geriatr Pharmacother 2011; 9: 364-77.

38 Zhou SF, Wang B, Yang LP, Liu JP. Structure, function, regulation and polymorphism and the clinical significance of human cytochrome P450 1A2. Drug Metab Rev 2010; 42: 268-354.

39 Liu L, Pan X, Liu HY, Liu XD, Yang HW, Xie L, et al. Modulation of pharmacokinetics of theophylline by antofloxacin, a novel 8-aminofluoroquinolone, in humans. Acta Pharmacol Sin 2011; 32: 1285-93.

40 O'Donnell JA, Gelone SP. Fluoroquinolones. Infect Dis Clin North Am 2000; 14: 489-513.

41 Zhang L, Wei MJ, Zhao CY, Qi HM. Determination of the inhibitory potential of 6 fluoroquinolones on CYP1A2 and CYP2C9 in human liver microsomes. Acta Pharmacol Sin 2008; 29: 1507-14. 